\title{
Glucose sensing by carotid body glomus cells: potential implications in disease
}

\author{
Lin Gao 1,2*, Patricia Ortega-Sáenz ${ }^{1,2,3}$, María García-Fernández ${ }^{3}$, Patricia González-Rodríguez ${ }^{1,2}$, \\ Candela Caballero-Eraso ${ }^{1,4}$ and José López-Barneo ${ }^{1,2,3 *}$ \\ ${ }^{1}$ Instituto de Biomedicina de Sevilla, Hospital Universitario Virgen del Rocío/Consejo Superior de Investigaciones Científicas/Universidad de Sevilla, Seville, Spain \\ ${ }^{2}$ Centro de Investigación Biomédica en Red sobre Enfermedades Neurodegenerativas, Seville, Spain \\ ${ }^{3}$ Departamento de Fisiología Médica y Biofísica, Facultad de Medicina, Universidad de Sevilla, Seville, Spain \\ ${ }^{4}$ Unidad Médico-Quirúrgica de Enfermedades Respiratorias, Hospital Universitario Virgen del Rocío, Seville, Spain
}

\section{Edited by:}

Rodrigo Iturriaga, Pontificia

Universidad Católica de Chile, Chile

Reviewed by:

Fiona D. McBryde, University of

Auckland, New Zealand

Prem Kumar, University of

Birmingham, UK

*Correspondence:

Lin Gao and José López-Barneo, Instituto de Biomedicina de Sevilla,

Hospital Universitario Virgen del

Rocío, Avda. Manuel Siurot, s/n,

41013-Seville, Spain

e-mail:Igao-ibis@us.es;

Ibarneo@us.es
The carotid body (CB) is a key chemoreceptor organ in which glomus cells sense changes in blood $\mathrm{O}_{2}, \mathrm{CO}_{2}$, and $\mathrm{pH}$ levels. $\mathrm{CB}$ glomus cells have also been found to detect hypoglycemia in both non-primate mammals and humans. $\mathrm{O}_{2}$ and low-glucose responses share a common final pathway involving membrane depolarization, extracellular calcium influx, increase in cytosolic calcium concentration, and neurotransmitter secretion, which stimulates afferent sensory fibers to evoke sympathoadrenal activation. On the other hand, hypoxia and low glucose induce separate signal transduction pathways. Unlike $\mathrm{O}_{2}$ sensing, the response of the CB to low glucose is not altered by rotenone, with the low glucose-activated background cationic current unaffected by hypoxia. Responses of the CB to hypoglycemia and hypoxia can be potentiated by each other. The counter-regulatory response to hypoglycemia by the $\mathrm{CB}$ is essential for the brain, an organ that is particularly sensitive to low glucose. CB glucose sensing could be altered in diabetic patients, particularly those under insulin treatment, as well as in other medical conditions such as sleep apnea or obstructive pulmonary diseases, where chronic hypoxemia presents with plastic modifications in $C B$ structure and function. The current review will focus on the following main aspects: (1) the $\mathrm{CB}$ as a low glucose sensor in both in vitro and in vivo models; (2) molecular and ionic mechanisms of low glucose sensing by glomus cells, (3) the interplay between low glucose and $\mathrm{O}_{2}$ sensing in $\mathrm{CB}$, and (4) the role of $\mathrm{CB}$ low glucose sensing in the pathophysiology of cardiorespiratory and metabolic diseases, and how this may serve as a potential therapeutic target.

Keywords: carotid body, glucose sensing, $\mathrm{O}_{2}$ sensing, hypoglycemia, intermittent hypoxia, sleep apnea, chronic hypoxia, diabetes

\section{INTRODUCTION}

Hypoglycemia, or a low blood glucose level, is a physiological condition that is detected by the body to trigger compensatory counter-regulatory responses, which are essential for maintaining glucose supply to organs, such as the brain, strictly dependent on this metabolite for survival. Alterations of glucose sensing might play an important pathogenic role in several diseases, especially those related to sympathoexcitation. The carotid body (CB) is a key chemoreceptor organ that may critically participate in glucose homeostasis. The first study linking the $\mathrm{CB}$ to glucose metabolism was reported more than 25 years ago (Alvarez-Buylla and de Alvarez-Buylla, 1988), and knowledge of the molecular mechanism underlying $\mathrm{CB}$ glucose sensing has advanced recently due in part to improvements in $\mathrm{CB}$ preparations that are suitable for in vitro recording of physiological parameters (Pardal and LopezBarneo, 2002a). The role of the CB in several cardiorespiratory and metabolic disorders has also been studied in the past few years (Paton et al., 2013; Ribeiro et al., 2013; Schultz et al., 2013) with the $\mathrm{CB}$ recently proposed as a potential therapeutic target for these diseases (McBryde et al., 2013).

\section{CAROTID BODY AND $0_{2}$ SENSING}

The $\mathrm{CB}$, the main arterial chemoreceptor, is located at the carotid artery bifurcation. The CB is composed of clusters (glomeruli) of electrically excitable neuron-like glomus (type I) cells surrounded by glia-like sustentacular (type II) cells. Type II cells, or a subpopulation of them, have recently been identified as neural stem cells that contribute to the growth of the organ in conditions of chronic hypoxemia (Pardal et al., 2007; Platero-Luengo et al., 2014). Type I glomus cells have secretory vesicles containing dopamine and other neurotransmitters. $\mathrm{CB}$ glomus cells sense changes in the chemical composition of blood, including $\mathrm{O}_{2}$ tension $\left(\mathrm{PO}_{2}\right), \mathrm{CO}_{2}$ tension, $\mathrm{pH}$, and other stimuli (reviewed by Lopez-Barneo et al., 2008; Kumar and Prabhakar, 2012).

A major physiological function of the $\mathrm{CB}$ is to sense changes in blood $\mathrm{PO}_{2}$, as this variable is not detected by central chemoreceptors. $\mathrm{CB}$ glomus cells behave as $\mathrm{O}_{2}$-sensitive presynaptic-like elements. During hypoxia, $\mathrm{O}_{2}$-sensitive $\mathrm{K}^{+}$channels are closed in the plasma membrane of glomus cells, which triggers membrane depolarization, $\mathrm{Ca}^{2+}$ influx, and neurotransmitter release. This signal is sent to the brainstem respiratory centers by afferent 
fibers of the carotid-sinus nerve to mediate a compensatory acute hyperventilatory response in order to increase $\mathrm{O}_{2}$ tension in the blood (Weir et al., 2005; Lopez-Barneo et al., 2008). Besides the $\mathrm{CB}$ glomus cells, $\mathrm{O}_{2}$-sensitive ion channels have been described in numerous cell classes, such as chromaffin cells in the adrenal medulla, neuroepithelial bodies of the lung, pulmonary and systemic vascular smooth muscle, and heart myocytes among others (see for review Lopez-Barneo et al., 1999, 2001).

\section{CAROTID BODY AND GLUCOSE SENSING GLUCOSE SENSING IN DIFFERENT ORGANS}

The brain is very sensitive to decreased glucose supply from the blood. Glucose-sensitive neurons have been found in different regions of the brain (Routh, 2002), including the hypothalamus (Biggers et al., 1989; Dunn-Meynell et al., 2002; Levin et al., 2004; Burdakov et al., 2006) and striatum (Calabresi et al., 1997) to mediate reflexes that counter-balance the changes of glucose level. Glucose-sensitive neurons have specific functional and molecular properties. Glut2, a low-affinity glucose transporter is expressed in some glucose-sensing cells (Schuit et al., 2001; Thorens, 2001). Glucokinase, a low-affinity hexokinase characteristic of pancreatic beta cells, seems to play an important role in both glucosestimulated and inhibited neurons (Dunn-Meynell et al., 2002). In addition to the well-established role of central neurons in glucose control, numerous pieces of evidence indicate that glucose sensors also exist at the periphery and that they have an essential physiological role (Cane et al., 1986). In addition to $\alpha$-cells of the pancreas, hypoglycemia-sensitive cells have also been suggested to exist in the liver (Hamilton-Wessler et al., 1994), near the portal vein (Hevener et al., 1997), and in the adrenal gland of the newborn (Livermore et al., 2012).

\section{CAROTID BODY AS A SENSOR OF LOW GLUCOSE}

The first evidence linking the $\mathrm{CB}$ with glucose metabolism was reported by Alvarez-Buylla and de Alvarez-Buylla (1988), Alvarez-Buylla and Roces de Alvarez-Buylla (1994). More recently, in vivo studies demonstrated that the counter-regulatory response to insulin-induced hypoglycemia is impaired in CBresected dogs (Koyama et al., 2000). Moreover, these animals exhibit suppressed exercise-mediated induction of arterial plasma glucagon and norepinephrine and, therefore, cannot maintain blood glucose levels during exercise (Koyama et al., 2001).

Direct molecular proof of the CB as a glucose-sensing organ was first reported by Pardal and López-Barneo using the CB thin slice preparation and amperometry techniques (Pardal and Lopez-Barneo, 2002b). In this in vitro system, rat CB glomus cells secrete neurotransmitter when exposed to a glucose-free solution (Figures 1A,B) (Garcia-Fernandez et al., 2007). This secretory activity is reversible, depending on external $\mathrm{Ca}^{2+}$ influx (Figure 1C), and is proportional to the degree of glucopenia. Responses to hypoglycemia, including neurotransmitter release and sensory fiber discharge, have also been observed in other in vitro studies using rat $\mathrm{CB}$ slices (Garcia-Fernandez et al., 2007; Zhang et al., 2007), rat CB/petrosal ganglion co-culture (Zhang et al., 2007), and cat CB (Fitzgerald et al., 2009). Recently, the hypoglycemia-mediated secretory response has also been detected in human glomus cells dispersed from post mortem
CBs (Ortega-Saenz et al., 2013) (see below). However, this topic is controversial as other groups have failed to detect glucose sensing by explanted CBs or dissociated rat CB cells (Bin-Jaliah et al., 2004; Gallego-Martin et al., 2012). Bin-Jaliah et al. (2004) reported $\mathrm{CB}$ stimulation in rats secondary to insulin-induced hypoglycemia. However, they proposed that sensing of hypoglycemia by the CB could be an indirect phenomenon dependent on other metabolically mediated blood borne factor. Systemic studies performed in humans have also reported opposing results regarding the role of the $\mathrm{CB}$ in hormonal counter-regulatory responses to hypoglycemia (Ward et al., 2009; Wehrwein et al., 2010). Although not fully understood, these discrepancies could possibly result from differences in CB sample preparation or limitations in experimental design. In any event, taken together the available experimental data suggests that low glucose sensing by CBs is likely to be a general phenomenon among mammals that has potential pathophysiological implications.

\section{MOLECULAR AND IONIC MECHANISMS OF LOW GLUCOSE SENSING BY CAROTID BODY GLOMUS CELLS}

The molecular mechanisms underlying CB glomus cell activation by hypoglycemia have been investigated in both lower mammals and human CB tissue samples (Pardal and Lopez-Barneo, 2002b; Garcia-Fernandez et al., 2007; Zhang et al., 2007; Fitzgerald et al., 2009; Ortega-Saenz et al., 2013). In our initial study we reported that, like $\mathrm{O}_{2}$ sensing by the $\mathrm{CB}$, macroscopic voltage-gated outward $\mathrm{K}^{+}$currents are inhibited in patch-clamped rat glomus cells exposed to glucose-free solutions (Pardal and Lopez-Barneo, $2002 \mathrm{~b}$ ). However, we soon realized that besides this phenomenon, low glucose elicits a membrane depolarization of $\sim 8 \mathrm{mV}$ (Figures 1D,E) (Garcia-Fernandez et al., 2007), which is the main process leading to extracellular $\mathrm{Ca}^{2+}$ influx into glomus cells, as demonstrated by microfluorimetry experiments using Fura-2AM labeled cells (Figure 1F) (Pardal and Lopez-Barneo, 2002b; Garcia-Fernandez et al., 2007; Ortega-Saenz et al., 2013). The increase in intracellular $\mathrm{Ca}^{2+}$, which is demonstrated by the inhibition of the secretory activity by $\mathrm{Cd}^{2+}$, a blocker of voltagegated $\mathrm{Ca}^{2+}$ channels (Pardal and Lopez-Barneo, 2002b; GarciaFernandez et al., 2007), results in exocytotic neurotransmitter release (Pardal and Lopez-Barneo, 2002b; Garcia-Fernandez et al., 2007; Zhang et al., 2007; Ortega-Saenz et al., 2013). This neurotransmitter release triggers afferent discharge and activation of counter-regulatory autonomic pathways to increase the blood glucose level (Zhang et al., 2007; Fitzgerald et al., 2009). The depolarizing receptor potential triggered by low glucose has a reversal potential above $0 \mathrm{mV}$ and is due to the increase of a standing inward cationic current (carried preferentially by $\mathrm{Na}^{+}$ions) present in glomus cells (Figures 1G,H) (Garcia-Fernandez et al., 2007). Indeed, in contrast with hypoxia, low glucose decreases the membrane resistance of glomus cells recorded with the perforated patch configuration of the patch clamp technique to $~ 50 \%$ of control (González-Rodríguez and López-Barneo, unpublished results). As reported by others (Carpenter and Peers, 2001), the background $\mathrm{Na}^{+}$current plays a major role in chemotransduction by glomus cells as it sets the membrane potential to relatively depolarized levels, near the threshold for the opening of $\mathrm{Ca}^{2+}$ channels. 


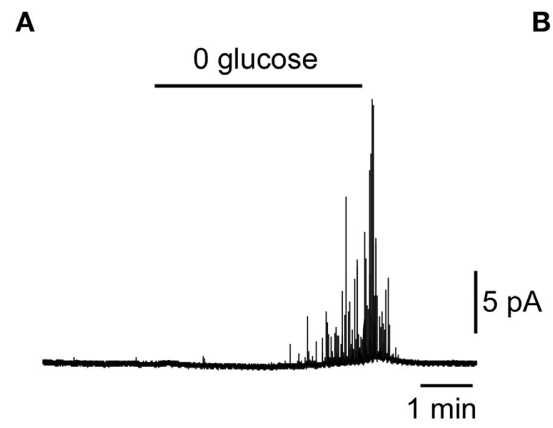

D

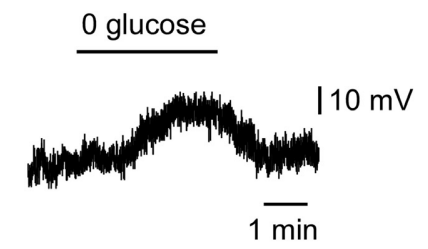

G

Voltage-clamp

$(-80 \mathrm{mV})$

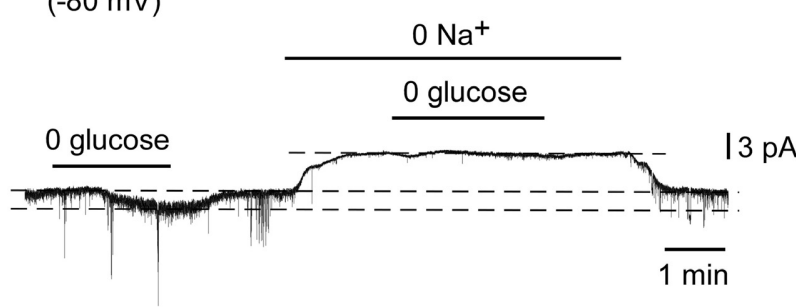

H

Current-clamp

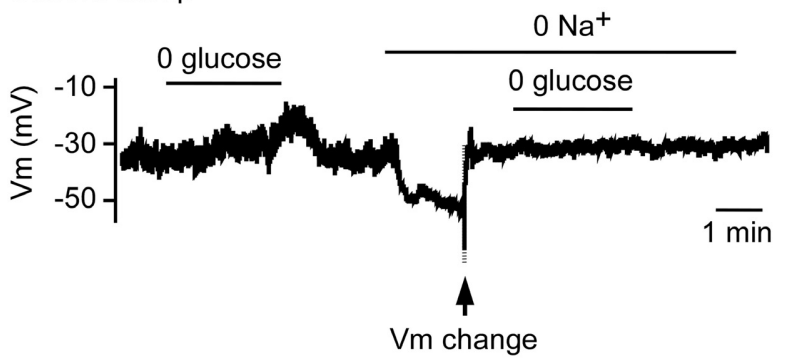

C

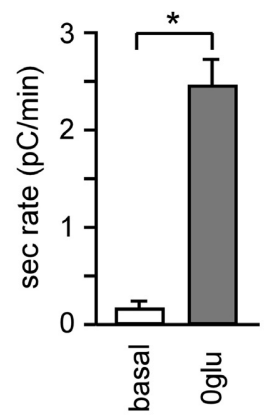

E
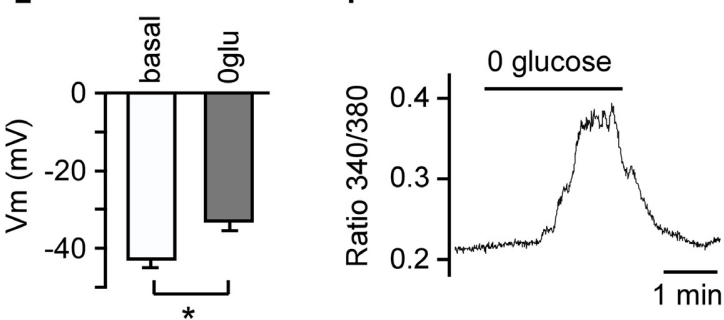

FIGURE 1 | Counter-regulatory response to hypoglycemia in rat carotid body (CB) slices and isolated glomus cells. A representative secretory response (A) and average secretion rate (B) induced by glucopenia in glomus cells from CB slices $(n=3)$. (C) Abolition of the secretory response to hypoglycemia by $100 \mu \mathrm{M} \mathrm{Cd}^{2+}$. A representative depolarizing receptor potential (D) and average membrane potential (E) induced by 0 glucose in CB glomus cells $(n=25)$. (F) Reversible increase in cytosolic $\mathrm{Ca}^{2+}$ concentration in a Fura-2-loaded glomus cell in response to 0 glucose. (G) Abolition of 0 glucose-induced increase in current (Icontrol-IOglu) by replacement of extracellular $\mathrm{Na}^{+}$with $\mathrm{N}$-methyl-D-glucamine $\left(\mathrm{O} \mathrm{Na}^{+}\right)$in voltage-clamped glomus cells $(n=3)$. $(\mathbf{H})$ Inhibition of 0 glucose-induced depolarization ( $\mathrm{V}$ control-VOglu) by replacement of extracellular $\mathrm{Na}^{+}$with $\mathrm{N}$-methyl-D-glucamine $\left(0 \mathrm{Na}^{+}\right)$in current-clamped glomus cells $(n=3)$. To compensate for the hyperpolarization induced by $0 \mathrm{Na}^{+}, \mathrm{Vm}$ was changed manually to the previous resting value (arrow) ${ }^{*} p<0.05$ (Modified from Garcia-Fernandez et al., 2007).

\section{GLUCOSE TRANSPORT AND METABOLISM IN THE CAROTID BODY} DURING LOW GLUCOSE SENSING

The mechanism of low glucose sensing by CB glomus cells does not seem to be the same as high glucose sensing by other glucosesensing cells in terms of glucose transport and metabolism.
Glut2 and glucokinase, molecules specifically expressed in high glucose-sensing cells (Schuit et al., 2001; Thorens, 2001), are not expressed in the CB (Garcia-Fernandez et al., 2007). However, glucose metabolism appears to be necessary for low glucose sensing by the $\mathrm{CB}$, since non-metabolizable glucose fails to prevent the 
glucose deficiency-induced catecholamine secretion by glomus cells (Garcia-Fernandez et al., 2007).

\section{REGULATION OF CAROTID BODY LOW GLUCOSE SENSING SIMILARITIES AND DIFFERENCES BETWEEN LOW GLUCOSE AND $\mathrm{O}_{2}$ SENSING}

$\mathrm{O}_{2}$ and low-glucose sensing by the $\mathrm{CB}$ share many similarities. Both signaling pathways involve the inhibition of voltagegated $\mathrm{K}^{+}$channels, plasma membrane depolarization, influx of extracellular $\mathrm{Ca}^{2+}$, neurotransmitter release, and afferent nerve firing to transmit the signal to the brain, in order to trigger counter-regulatory responses to increase blood $\mathrm{O}_{2}$ tension and glucose concentration. On the other hand, the initial steps of the signaling pathways are different for each. Low glucose triggers a depolarizing receptor potential, which is dependent on the activation of background cationic $\mathrm{Na}^{+}$-permeable channels (Garcia-Fernandez et al., 2007), which do not seem to be regulated by hypoxia (Carpenter and Peers, 2001). Although voltage-gated $\mathrm{K}^{+}$channels are inhibited upon exposure of $\mathrm{CB}$ glomus cells to low glucose, this inhibition has a minimal effect regarding neurotransmitter secretion (Garcia-Fernandez et al., 2007). Indeed, as stated above, low glucose induces a decrease in the input resistance of cells, whereas the predominant effect of hypoxia is an increase in input resistance. Although glomus cells normally secrete neurotransmitters in response to glucose and hypoxia, there are cells that respond to only one of these two stimuli (Figures 2A,B). Moreover, rotenone, a specific mitochondrial complex I inhibitor, which blocks hypoxia-induced catecholamine secretion (Ortega-Saenz et al., 2003), shows no effect on the low glucose-induced secretory activity in CB cells (Figures 2C,D) (Garcia-Fernandez et al., 2007). Therefore, it appears that sensitivities to hypoglycemia and hypoxia depend on separate signal transduction mechanisms, although they share the same final steps leading to transmembrane $\mathrm{Ca}^{2+}$ influx and neurotransmitter release. The mechanism of $\mathrm{CB} \mathrm{O}_{2}$ sensing is as yet unknown; however a considerable body of knowledge including our rotenone data, suggests that mitochondria may play an important direct or indirect role (Ortega-Saenz
A

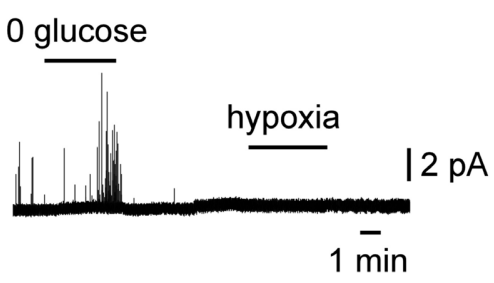

C
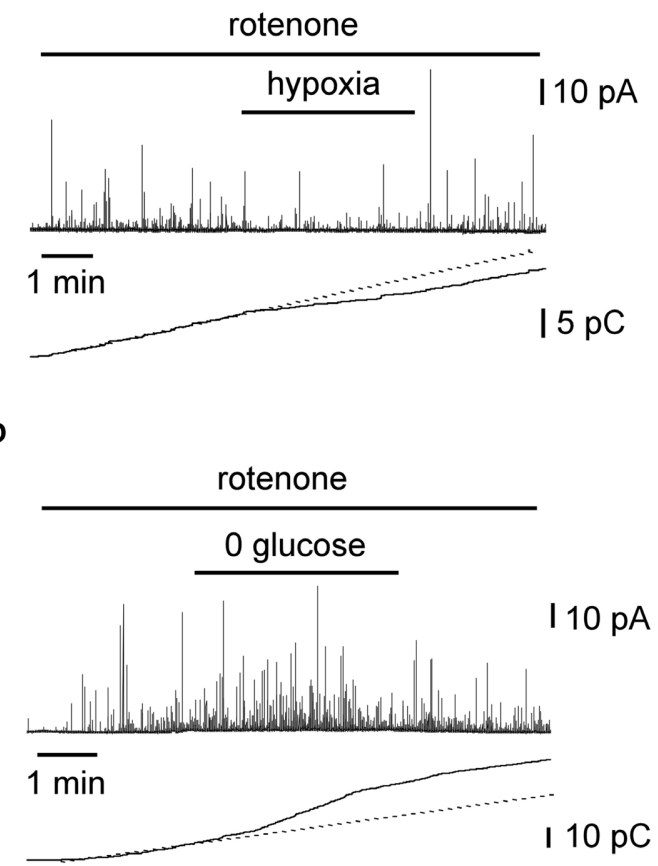

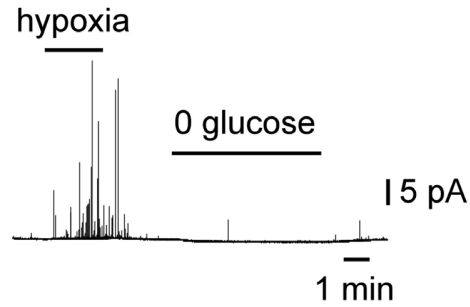

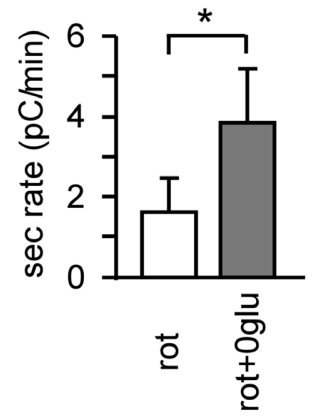

FIGURE 2 | Differential sensitivity of glomus cells to oxygen and low glucose in rat carotid body slices. $(\mathbf{A}, \mathbf{B})$ Examples of cells with differential secretory responses to hypoxia and low glucose. Differential effect of $100 \mathrm{nM}$ rotenone on the secretory response induced by hypoxia
(C) ( $n=14)$ and hypoglycemia (D) $(n=5)$, as demonstrated by a representative amperometric recording, cumulative secretion signal, and average secretion rate. ${ }^{*} p<0.05$ (Modified from Garcia-Fernandez et al., 2007). 
et al., 2003; see Buckler and Turner, 2013 for an update and references). The fact that rotenone does not alter glomus cell responses to hypoglycemia indicates that low glucose sensing is not related to oxidative phosphorylation and could depend on metabolites of the glycolytic pathway (Garcia-Fernandez et al., 2007).

\section{INTERPLAY BETWEEN LOW GLUCOSE AND $\mathbf{0}_{2}$ SENSING}

The brain is very sensitive to decreases both in arterial $\mathrm{O}_{2}$ tension and glucose level. Being a polymodal sensor of $\mathrm{O}_{2}$, glucose, $\mathrm{pH}$, $\mathrm{CO}_{2}$, etc., a coordinated response to hypoxia and hypoglycemia by $\mathrm{CB}$ chemoreceptors could prevent to a major extent the detrimental effects caused by both conditions. Although a small percentage of $\mathrm{CB}$ glomus cells respond specifically to only hypoxia or low glucose (Garcia-Fernandez et al., 2007), in a majority of glomus cells hypoxia and hypoglycemia can potentiate each other's response, such as is seen with neurotransmitter release and afferent discharge (Pardal and Lopez-Barneo, 2002b; Zhang et al., 2007; Fitzgerald et al., 2009). The secretory response to low glucose increases in the presence of low $\mathrm{PO}_{2}$ in rat CB slices (Pardal and Lopez-Barneo, 2002b), and we have recently shown that glomus cells in the human $\mathrm{CB}$ are also glucose sensors and show the same responses (cell depolarization, increased cytosolic $\mathrm{Ca}^{2+}$ and neurotransmitter secretion), as described in lower mammals (Figures 3A-D). In this preparation, hypoxia $\left(6 \% \mathrm{O}_{2}\right)$ potentiates low glucose-induced catecholamine secretion, whereas low glucose further induces $\mathrm{Ca}^{2+}$ influx during hypoxia (Figures 3D,E). The effect of hyperoxia on hypoglycemia and the effect of hyperglycemia on hypoxia are less well known. A recent human study suggested that hyperoxia could blunt the hypoglycemia effect (Wehrwein et al., 2010). Another study suggested that both hypo and hyperglycemia could increase the hypoxic response in human subjects (Ward et al., 2007).

\section{INTERMITTENT HYPOXIA AND GLUCOSE SENSING}

No direct evidence has been reported regarding the effect of intermittent hypoxia on glucose sensing by the CB. In rat CB glomus cells, intermittent hypoxia enhances acute hypoxia-induced membrane depolarization and the inhibition of TASK-like $\mathrm{K}^{+}$ channels (Ortiz et al., 2013). Intermittent hypoxia has also been found to augment the CB sensory response to acute hypoxia and to enhance the hypoxic ventilatory chemoreflex in neonatal rats (Peng et al., 2004). However, a recent study reported an exaggerated activation of $\mathrm{CB}$ afferent activity accompanied by hypoventilation in a rat model of intermittent hypoxia when exposed to acute hypoxia (Gonzalez-Martin et al., 2011). It is logical to speculate that intermittent hypoxia could potentiate the carotid chemoreceptor response to hypoglycemia, as occurs with hypoxia. Indeed, intermittent hypoxia has been found to be associated with altered glucose metabolism in rodent models. Intermittent hypoxia results in an increase in fasting glucose and a decrease in insulin level in neonatal rats, which is associated with a disturbed glucose homeostasis (Pae et al., 2013). In mouse, intermittent hypoxia triggers increased fasting glucose and decreased sensitivity to insulin, with the former being reversed by discontinuation of exposure to hypoxia (Polak et al., 2013). Few human studies have been carried out to study the relationship between intermittent hypoxia and glucose homeostasis. Individuals exposed to intermittent hypoxia demonstrate an increased sympathetic nerve activity (Cutler et al., 2004), while male adults exposed to high altitude hypoxia have decreased insulin sensitivity (Larsen et al., 1997).

\section{INSULIN AND CAROTID BODY GLUCOSE SENSING}

In addition to hypoxia and intermittent hypoxia, insulin was found recently to be a regulator of the $\mathrm{CB}$ response to hypoglycemia. Indeed, insulin was proposed as a new intermittent hypoxia-like agent, and carotid chemoreceptors have been suggested to contribute to insulin-mediated sympathoexcitation (Limberg et al., 2014). Animal studies indicate that CB cells have insulin receptors and respond to increases in insulin levels by inducing sympathetic activation, as demonstrated by altered arterial blood pressure, breathing, and neurotransmitter release (Bin-Jaliah et al., 2004; Ribeiro et al., 2013). The combined activation of $\mathrm{CB}$ chemoreceptors by insulin and low glucose may serve as a counter-balance mechanism to limit the decrease of glucose levels in insulin-treated patients. In this regard, it would be interesting to explore whether long-lasting $\mathrm{CB}$ exposure to high glucose, as occurs in diabetic patients, alters the low glucose sensitivity of glomus cells.

\section{CAROTID BODY DYSFUNCTION IN DISEASE STATES}

$\mathrm{CB}$ acts as a combined oxygen and glucose sensor to facilitate activation of the counter-regulatory measures in response to small reductions of either variable. Such measures include, on one hand, hyperventilation and increased blood pressure to facilitate blood-borne $\mathrm{O}_{2}$ supply to organs and, on the other hand liver glycogenolysis and insulin resistance of peripheral tissues to combat hypoglycemia. Diseases altering the structure and function of $\mathrm{CB}$ chemoreceptors could have detrimental effects, leading to dysregulation of glucose homeostasis.

\section{OBSTRUCTIVE SLEEP APNEA}

Obstructive sleep apnea (OSA) is a common clinical syndrome characterized by intermittent hypoxia and sleep fragmentation. OSA is a well-established significant risk factor for cardiovascular disease and mortality. As indicated above Intermittent Hypoxia and Glucose Sensing, chronic intermittent hypoxia results in $\mathrm{CB}$ chemoreceptor over-stimulation and augmentation of $\mathrm{CB}$ sensory responses in rats (Peng et al., 2003) and humans (Cutler et al., 2004). Intermittent hypoxia has been found to be associated with altered glucose metabolism and insulin resistance in rodent models (Pae et al., 2013; Polak et al., 2013), but its effects on glucose homeostasis in humans are as yet unstudied. It can be expected that CB overstimulation and growth seen in OSA patients (Nair et al., 2013; Abboud and Kumar, 2014) should lead to hyperglycemia and over-sensitivity to low glucose. Nevertheless, $\mathrm{O}_{2}$ and glucose act on separate sensing mechanisms in glomus cells and, in addition, OSA can be accompanied by hypertension and diabetes. Therefore, the impact of OSA syndrome on CB-mediated glucose homeostasis requires future studies using human CB tissue samples (Ortega-Saenz et al., 2013). 
A

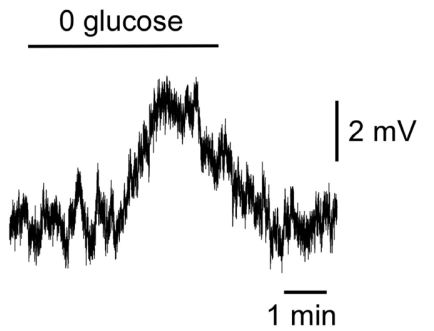

D

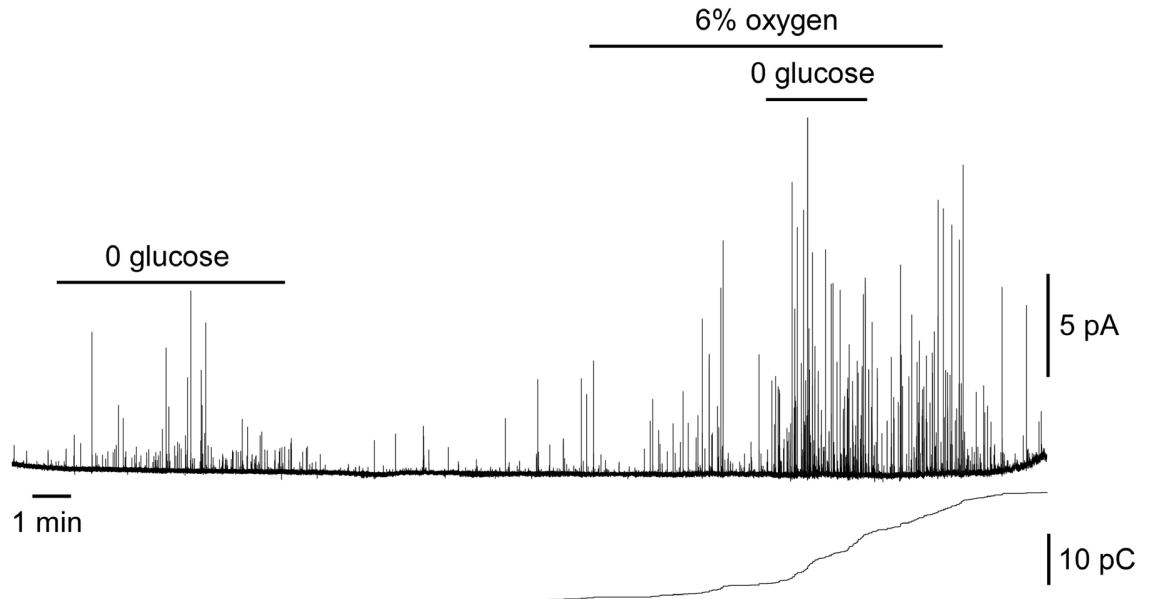

E

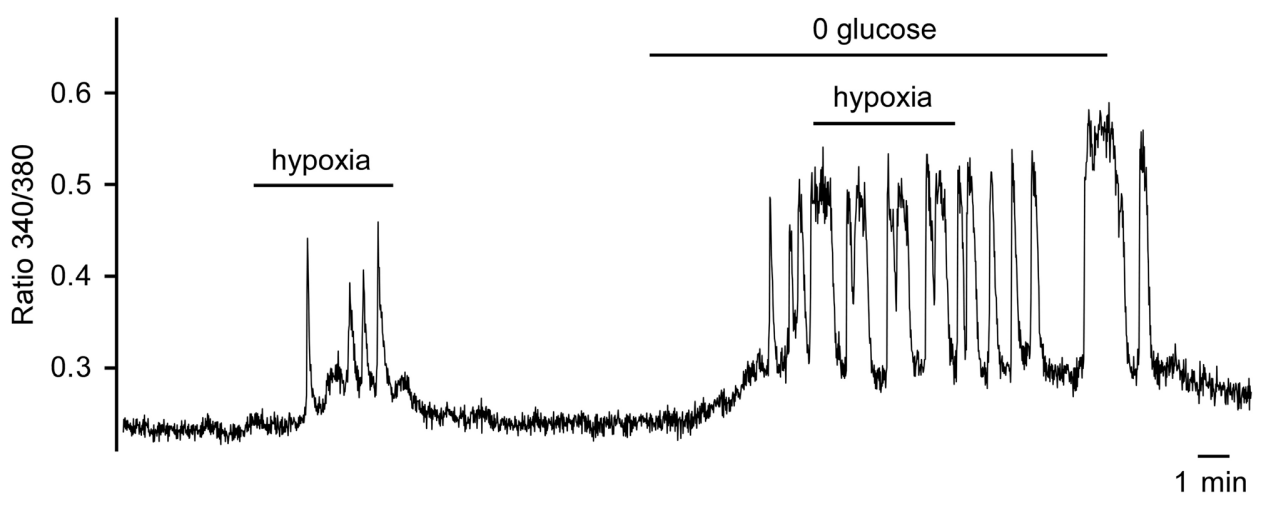

FIGURE 3 | Responses of human carotid body (CB) glomus cells to low glucose and hypoxia. (A) Depolarizing receptor potential recorded in a current-clamped human glomus cell in response to glucopenia. (B) Reversible increase in cytosolic $\mathrm{Ca}^{2+}$ in a Fura-2-loaded glomus cell exposed to 0 glucose. (C) Average secretion rate induced by hypoglycemia $(n=2)$. (D) Secretory response to 0 glucose of glomus cells in CB slices and the potentiation of the 0 glucose-induced secretory response by mild hypoxia $\left(6 \% \mathrm{O}_{2}\right)$ as demonstrated by a representative amperometric recording (top) and cumulative secretion signal (bottom). (E) Representative recording of a reversible increase of cytosolic $\mathrm{Ca}^{2+}$ in a Fura-2-loaded glomus cell, demonstrating the potentiation of the hypoxic-response by hypoglycemia. Modified from Ortega-Saenz et al. (2013).

\section{DIABETES}

Type 2 diabetes is a major chronic disease associated with high morbidity, mortality, and economic burden. Glucose sensing is essential for insulin-treated diabetic patients to counter-regulate insulin-induced hypoglycemia. It has been proposed that the $\mathrm{CB}$ dysfunction, increasing sympathetic tone and catecholamines in the blood, could possibly contribute to the pathogenesis of type 2 diabetes and essential hypertension (Nimbkar and Lateef, 2005). Using a computed tomographic angiography technique, enlargement of the $\mathrm{CB}$ is observed in patients with diabetes mellitus, hypertension, and congestive heart failure relative to controls, which supports the proposed functional relationship between 
the $\mathrm{CB}$ and sympathetically mediated disease states (Cramer et al., 2014). In insulin-dependent diabetic rats, the CB volume is increased, due to an increase in the extravascular volume (Clarke et al., 1999). It is still unclear whether the CB enlargement is a cause of diseases or a consequence of disease progression. Whether CB glucose sensing is altered in diabetic patients is also unknown (see below).

\section{RELATIONSHIP BETWEEN OBSTRUCTIVE SLEEP APNEA AND DIABETES}

OSA syndrome and type 2 diabetes are also strongly linked to each other. Patients with OSA have an increased incidence of impaired glucose metabolism and are at an increased risk of developing type 2 diabetes (Tasali et al., 2008). On the other hand, the majority of patients with type 2 diabetes also have OSA (Tasali et al., 2008). Although the mechanism is most likely multifactorial, chronic intermittent hypoxia experienced by OSA patients could trigger CB chemoreceptor over-activity, leading to insulin resistance and abnormal glucose metabolism (Tasali et al., 2008). Indeed, insulin resistance is developed in both lean mice (Iiyori et al., 2007) and genetically obese mice (Polotsky et al., 2003) treated with intermittent hypoxia. The secretory activity of the $\mathrm{CB}$ is increased in the insulin-resistant rat model, whereas carotid sinus nerve resection prevents $\mathrm{CB}$ over-activation and diet-induced insulin resistance (Ribeiro et al., 2013). Therefore, sympathoexcitation due to $\mathrm{CB}$ over-stimulation could play an important role in the pathogenesis of both OSA and type 2 diabetes.

\section{CONCLUSIONS}

Carotid chemoreceptors work in coordination with other glucose sensing organs to counter-regulate hypoxia and hypoglycemia. The responses to hypoxia and hypoglycemia could be potentiated by each other. Failure to respond to these stresses could lead to malfunction of organs, such as the brain, which is highly sensitive to glucose and $\mathrm{O}_{2}$ levels. Indeed, defects in $\mathrm{CB}$ function have been associated with several respiratory disturbances, particularly in the newborn (reviewed by Lopez-Barneo et al., 2008). $\mathrm{CB}$ over-stimulation could also exert detrimental effects, as has been demonstrated in OSA, hypertension and type 2 diabetes. However, whether the intrinsic glucose responsiveness of glomus cells is altered in these diseases is yet to be determined. Due to the essential role of the $\mathrm{CB}$ in sympathetic activation, this organ could serve as a potential therapeutic target for diseases with sustained hyperinsulinemia and sympathoexcitation, such as obesity, hypertension, sleep apnea, metabolic syndrome, cardiovascular disease, and diabetes (Paton et al., 2013). Evaluation of CB size in these conditions can be now studied with noninvasive computed tomography angiography (Nair et al., 2013; Cramer et al., 2014). However, bilateral surgical ablation of the CB performed in asthmatic patients or during neck tumor surgery causes permanent abolition of the ventilatory response to hypoxia. In addition, this condition causes a decrease in the $\mathrm{CO}_{2}$ sensitivity of the respiratory center and, in some cases, long term resting hypoventilation and hypercapnia (reviewed by Timmers et al., 2003, see also Dahan et al., 2007). The counter-regulatory response to hypoglycemia could be also altered in patients who have had their CB removed, a status particularly critical in diabetic patients subjected to insulin treatment and therefore at high risk of hypoglycemia. Unilateral CB resection appears to be well tolerated (reviewed by Timmers et al., 2003, see also MinguezCastellanos et al., 2007), thus making this likely to be a safer therapeutic option. Ideally, new reversible pharmacological tools should be developed to inhibit CB function. In this regard, selective inhibition of the $\mathrm{O}_{2}$-sensing mechanisms or $\mathrm{CB}$ growth in chronic hypoxia (Platero-Luengo et al., 2014) could reduce CB over-activation while maintaining intact the counter-regulatory response to low glucose.

\section{ACKNOWLEDGMENTS}

This research was supported by the Botín Foundation and the Spanish Ministry of Economy and Innovation (SAF program).

\section{REFERENCES}

Abboud, F., and Kumar, R. (2014). Obstructive sleep apnea and insight into mechanisms of sympathetic overactivity. J. Clin. Invest. 124, 1454-1457. doi: 10.1172/JCI70420

Alvarez-Buylla, R., and de Alvarez-Buylla, E. R. (1988). Carotid sinus receptors participate in glucose homeostasis. Respir. Physiol. 72, 347-359. doi: 10.1016/0034-5687(88)90093-X

Alvarez-Buylla, R., and Roces de Alvarez-Buylla, E. (1994). Changes in blood glucose concentration in the carotid body-sinus modify brain glucose retention. Brain Res. 654, 167-170. doi: 10.1016/0006-8993(94)91585-7

Biggers, D. W., Myers, S. R., Neal, D., Stinson, R., Cooper, N. B., Jaspan, J. B., et al. (1989). Role of brain in counterregulation of insulin-induced hypoglycemia in dogs. Diabetes 38, 7-16. doi: 10.2337/diab.38.1.7

Bin-Jaliah, I., Maskell, P. D., and Kumar, P. (2004). Indirect sensing of insulininduced hypoglycaemia by the carotid body in the rat. J. Physiol. 556, 255-266. doi: 10.1113/jphysiol.2003.058321

Buckler, K. J., and Turner, P. J. (2013). Oxygen sensitivity of mitochondrial function in rat arterial chemoreceptor cells. J. Physiol. 591, 3549-3563. doi: 10.1113/jphysiol.2013.257741

Burdakov, D., Jensen, L. T., Alexopoulos, H., Williams, R. H., Fearon, I. M., O’Kelly, I., et al. (2006). Tandem-pore $\mathrm{K}^{+}$channels mediate inhibition of orexin neurons by glucose. Neuron 50, 711-722. doi: 10.1016/j.neuron.2006.04.032

Calabresi, P., Ascone, C. M., Centonze, D., Pisani, A., Sancesario, G., D’Angelo, V., et al. (1997). Opposite membrane potential changes induced by glucose deprivation in striatal spiny neurons and in large aspiny interneurons. J. Neurosci. 17, 1940-1949.

Cane, P., Artal, R., and Bergman, R. N. (1986). Putative hypothalamic glucoreceptors play no essential role in the response to moderate hypoglycemia. Diabetes 35, 268-277. doi: 10.2337/diab.35.3.268

Carpenter, E., and Peers, C. (2001). A standing $\mathrm{Na}^{+}$conductance in rat carotid body type I cells. Neuroreport 12, 1421-1425. doi: 10.1097/00001756200105250-00025

Clarke, J. A., Daly Mde, B., Ead, H. W., and Hennessy, E. M. (1999). The carotid body of the spontaneous insulin-dependent diabetic rat. Braz. J. Med. Biol. Res. 32, 85-91. doi: 10.1590/S0100-879X1999000100013

Cramer, J. A., Wiggins, R. H., Fudim, M., Engelman, Z. J., Sobotka, P. A., and Shah, L. M. (2014). Carotid body size on CTA: correlation with comorbidities. Clin. Radiol. 69, e33-e36. doi: 10.1016/j.crad.2013.08.016

Cutler, M. J., Swift, N. M., Keller, D. M., Wasmund, W. L., and Smith, M. L. (2004). Hypoxia-mediated prolonged elevation of sympathetic nerve activity after periods of intermittent hypoxic apnea. J. Appl. Physiol. (1985) 96, 754-761. doi: 10.1152/japplphysiol.00506.2003

Dahan, A., Nieuwenhuijs, D., and Teppema, L. (2007). Plasticity of central chemoreceptors: effect of bilateral carotid body resection on central $\mathrm{CO}_{2}$ sensitivity. PLoS Med. 4:e239. doi: 10.1371/journal.pmed.00 40239

Dunn-Meynell, A. A., Routh, V. H., Kang, L., Gaspers, L., and Levin, B. E. (2002). Glucokinase is the likely mediator of glucosensing in both glucoseexcited and glucose-inhibited central neurons. Diabetes 51, 2056-2065. doi: 10.2337/diabetes.51.7.2056 
Fitzgerald, R. S., Shirahata, M., Chang, I., and Kostuk, E. (2009). The impact of hypoxia and low glucose on the release of acetylcholine and ATP from the incubated cat carotid body. Brain Res. 1270, 39-44. doi: 10.1016/j.brainres.2009.02.078

Gallego-Martin, T., Fernandez-Martinez, S., Rigual, R., Obeso, A., and Gonzalez, C. (2012). Effects of low glucose on carotid body chemoreceptor cell activity studied in cultures of intact organs and in dissociated cells. Am. J. Physiol. Cell Physiol. 302, C1128-C1140. doi: 10.1152/ajpcell.00196.2011

Garcia-Fernandez, M., Ortega-Saenz, P., Castellano, A., and Lopez-Barneo, J. (2007). Mechanisms of low-glucose sensitivity in carotid body glomus cells. Diabetes 56, 2893-2900. doi: 10.2337/db07-0122

Gonzalez-Martin, M. C., Vega-Agapito, M. V., Conde, S. V., Castaneda, J., Bustamante, R., Olea, E., et al. (2011). Carotid body function and ventilatory responses in intermittent hypoxia. Evidence for anomalous brainstem integration of arterial chemoreceptor input. J. Cell. Physiol. 226, 1961-1969. doi: $10.1002 /$ jcp. 22528

Hamilton-Wessler, M., Bergman, R. N., Halter, J. B., Watanabe, R. M., and Donovan, C. M. (1994). The role of liver glucosensors in the integrated sympathetic response induced by deep hypoglycemia in dogs. Diabetes 43, 1052-1060. doi: 10.2337/diab.43.8.1052

Hevener, A. L., Bergman, R. N., and Donovan, C. M. (1997). Novel glucosensor for hypoglycemic detection localized to the portal vein. Diabetes 46, 1521-1525. doi: 10.2337/diab.46.9.1521

Iiyori, N., Alonso, L. C., Li, J., Sanders, M. H., Garcia-Ocana, A., O’Doherty, R. M., et al. (2007). Intermittent hypoxia causes insulin resistance in lean mice independent of autonomic activity. Am. J. Respir. Crit. Care Med. 175, 851-857. doi: 10.1164/rccm.200610-1527OC

Koyama, Y., Coker, R. H., Denny, J. C., Lacy, D. B., Jabbour, K., Williams, P. E., et al. (2001). Role of carotid bodies in control of the neuroendocrine response to exercise. Am. J. Physiol. Endocrinol. Metab. 281, E742-E748.

Koyama, Y., Coker, R. H., Stone, E. E., Lacy, D. B., Jabbour, K., Williams, P. E., et al. (2000). Evidence that carotid bodies play an important role in glucoregulation in vivo. Diabetes 49, 1434-1442. doi: 10.2337/diabetes.49.9.1434

Kumar, P., and Prabhakar, N. R. (2012). Peripheral chemoreceptors: function and plasticity of the carotid body. Compr. Physiol. 2, 141-219. doi: 10.1002/cphy.c100069

Larsen, J. J., Hansen, J. M., Olsen, N. V., Galbo, H., and Dela, F. (1997). The effect of altitude hypoxia on glucose homeostasis in men. J. Physiol. 504(Pt 1), 241-249. doi: 10.1111/j.1469-7793.1997.241bf.x

Levin, B. E., Routh, V. H., Kang, L., Sanders, N. M., and Dunn-Meynell, A. A (2004). Neuronal glucosensing: what do we know after 50 years? Diabetes 53 , 2521-2528. doi: 10.2337/diabetes.53.10.2521

Limberg, J. K., Curry, T. B., Prabhakar, N. R., and Joyner, M. J. (2014). Is insulin the new intermittent hypoxia? Med. Hypotheses 82, 730-735. doi: 10.1016/j.mehy.2014.03.014

Livermore, S., Piskuric, N. A., Salman, S., and Nurse, C. A. (2012). Developmental regulation of glucosensing in rat adrenomedullary chromaffin cells: potential role of the K(ATP) channel. Adv. Exp. Med. Biol. 758, 191-198. doi: 10.1007/97894-007-4584-1_27

Lopez-Barneo, J., Ortega-Saenz, P., Pardal, R., Pascual, A., and Piruat, J. I. (2008). Carotid body oxygen sensing. Eur. Respir. J. 32, 1386-1398. doi: 10.1183/09031936.00056408

Lopez-Barneo, J., Pardal, R., Montoro, R. J., Smani, T., Garcia-Hirschfeld, J., and Urena, J. (1999). $\mathrm{K}^{+}$and $\mathrm{Ca}^{2+}$ channel activity and cytosolic $\left[\mathrm{Ca}^{2+}\right]$ in oxygen-sensing tissues. Respir. Physiol. 115, 215-227. doi: 10.1016/S00345687(99)00016-X

Lopez-Barneo, J., Pardal, R., and Ortega-Saenz, P. (2001). Cellular mechanism of oxygen sensing. Annu. Rev. Physiol. 63, 259-287. doi: 10.1146/annurev.physiol.63.1.259

McBryde, F. D., Abdala, A. P., Hendy, E. B., Pijacka, W., Marvar, P., Moraes, D. J., et al. (2013). The carotid body as a putative therapeutic target for the treatment of neurogenic hypertension. Nat. Commun. 4:2395. doi: 10.1038/ncomms3395

Minguez-Castellanos, A., Escamilla-Sevilla, F., Hotton, G. R., Toledo-Aral, J. J., Ortega-Moreno, A., Mendez-Ferrer, S., et al. (2007). Carotid body autotransplantation in Parkinson disease: a clinical and positron emission tomography study. J. Neurol. Neurosurg. Psychiatr. 78, 825-831. doi: 10.1136/jnnp.2006.106021

Nair, S., Gupta, A., Fudim, M., Robinson, C., Ravi, V., Hurtado-Rua, S., et al. (2013). CT angiography in the detection of carotid body enlargement in patients with hypertension and heart failure. Neuroradiology 55, 1319-1322. doi: $10.1007 / \mathrm{s} 00234-013-1273-3$

Nimbkar, N. V., and Lateef, F. (2005). Carotid body dysfunction: the possible etiology of non-insulin dependent diabetes mellitus and essential hypertension. Med. Hypotheses 65, 1067-1075. doi: 10.1016/j.mehy.2005.06.023

Ortega-Saenz, P., Pardal, R., Garcia-Fernandez, M., and Lopez-Barneo, J. (2003). Rotenone selectively occludes sensitivity to hypoxia in rat carotid body glomus cells. J. Physiol. 548, 789-800. doi: 10.1113/jphysiol.2003.039693

Ortega-Saenz, P., Pardal, R., Levitsky, K., Villadiego, J., Munoz-Manchado, A. B., Duran, R., et al. (2013). Cellular properties and chemosensory responses of the human carotid body. J. Physiol. 591, 6157-6173. doi: 10.1113/jphysiol.2013.263657

Ortiz, F. C., Del Rio, R., Ebensperger, G., Reyes, V. R., Alcayaga, J., Varas, R., et al. (2013). Inhibition of rat carotid body glomus cells TASK-like channels by acute hypoxia is enhanced by chronic intermittent hypoxia. Respir. Physiol. Neurobiol. 185, 600-607. doi: 10.1016/j.resp.2012.11.015

Pae, E. K., Ahuja, B., Kim, M., and Kim, G. (2013). Impaired glucose homeostasis after a transient intermittent hypoxic exposure in neonatal rats. Biochem. Biophys. Res. Commun. 441, 637-642. doi: 10.1016/j.bbrc.2013.10.102

Pardal, R., and Lopez-Barneo, J. (2002a). Carotid body thin slices: responses of glomus cells to hypoxia and $\mathrm{K}(+)$-channel blockers. Respir. Physiol. Neurobiol. 132, 69-79. doi: 10.1016/S1569-9048(02)00050-2

Pardal, R., and Lopez-Barneo, J. (2002b). Low glucose-sensing cells in the carotid body. Nat. Neurosci. 5, 197-198. doi: 10.1038/nn812

Pardal, R., Ortega-Saenz, P., Duran, R., and Lopez-Barneo, J. (2007). Glia-like stem cells sustain physiologic neurogenesis in the adult mammalian carotid body. Cell 131, 364-377. doi: 10.1016/j.cell.2007.07.043

Paton, J. F., Sobotka, P. A., Fudim, M., Engelman, Z. J., Hart, E. C., McBryde, F. D., et al. (2013). The carotid body as a therapeutic target for the treatment of sympathetically mediated diseases. Hypertension 61, 5-13. doi: 10.1161/HYPERTENSIONAHA.111.00064

Peng, Y. J., Overholt, J. L., Kline, D., Kumar, G. K., and Prabhakar, N. R. (2003). Induction of sensory long-term facilitation in the carotid body by intermittent hypoxia: implications for recurrent apneas. Proc. Natl. Acad. Sci. U.S.A. 100, 10073-10078. doi: 10.1073/pnas.1734109100

Peng, Y. J., Rennison, J., and Prabhakar, N. R. (2004). Intermittent hypoxia augments carotid body and ventilatory response to hypoxia in neonatal rat pups. J. Appl. Physiol. (1985) 97, 2020-2025. doi: 10.1152/japplphysiol.00876.2003

Platero-Luengo, A., Gonzalez-Granero, S., Duran, R., Diaz-Castro, B., Piruat, J. I., Garcia-Verdugo, J. M., et al. (2014). An $\mathrm{O}_{2}$-sensitive glomus cell-stem cell synapse induces carotid body growth in chronic hypoxia. Cell 156, 291-303. doi: 10.1016/j.cell.2013.12.013

Polak, J., Shimoda, L. A., Drager, L. F., Undem, C., McHugh, H., Polotsky, V. Y., et al. (2013). Intermittent hypoxia impairs glucose homeostasis in C57BL6/J mice: partial improvement with cessation of the exposure. Sleep 36, 1483-1490; 1490A-1490B. doi: 10.5665/sleep.3040

Polotsky, V. Y., Li, J., Punjabi, N. M., Rubin, A. E., Smith, P. L., Schwartz, A. R., et al. (2003). Intermittent hypoxia increases insulin resistance in genetically obese mice. J. Physiol. 552, 253-264. doi: 10.1113/jphysiol.2003.048173

Ribeiro, M. J., Sacramento, J. F., Gonzalez, C., Guarino, M. P., Monteiro, E. C., and Conde, S. V. (2013). Carotid body denervation prevents the development of insulin resistance and hypertension induced by hypercaloric diets. Diabetes 62, 2905-2916. doi: 10.2337/db12-1463

Routh, V. H. (2002). Glucose-sensing neurons: are they physiologically relevant? Physiol. Behav. 76, 403-413. doi: 10.1016/S0031-9384(02)00761-8

Schuit, F. C., Huypens, P., Heimberg, H., and Pipeleers, D. G. (2001). Glucose sensing in pancreatic beta-cells: a model for the study of other glucose-regulated cells in gut, pancreas, and hypothalamus. Diabetes 50, 1-11. doi: 10.2337/diabetes.50.1.1

Schultz, H. D., Marcus, N. J., and Del Rio, R. (2013). Role of the carotid body in the pathophysiology of heart failure. Curr. Hypertens. Rep. 15, 356-362. doi: 10.1007/s11906-013-0368-x

Tasali, E., Mokhlesi, B., and Van Cauter, E. (2008). Obstructive sleep apnea and type 2 diabetes: interacting epidemics. Chest 133, 496-506. doi: 10.1378/chest. 07-0828

Thorens, B. (2001). GLUT2 in pancreatic and extra-pancreatic gluco-detection (review). Mol. Membr. Biol. 18, 265-273. doi: 10.1080/09687680110100995

Timmers, H. J., Karemaker, J. M., Wieling, W., Marres, H. A., Folgering, H. T., and Lenders, J. W. (2003). Baroreflex and chemoreflex function after bilateral carotid 
body tumor resection. J. Hypertens. 21, 591-599. doi: 10.1097/00004872200303000-00026

Ward, D. S., Voter, W. A., and Karan, S. (2007). The effects of hypo- and hyperglycaemia on the hypoxic ventilatory response in humans. J. Physiol. 582, 859-869. doi: $10.1113 /$ jphysiol.2007.130112

Ward, D. S., Voter, W. A., and Karan, S. (2009). The role of the carotid bodies in the counter-regulatory response to hypoglycemia. Adv. Exp. Med. Biol. 648, 273-280. doi: 10.1007/978-90-481-2259-2_31

Wehrwein, E. A., Basu, R., Basu, A., Curry, T. B., Rizza, R. A., and Joyner, M. J. (2010). Hyperoxia blunts counterregulation during hypoglycaemia in humans: possible role for the carotid bodies? J. Physiol. 588, 4593-4601. doi: 10.1113/jphysiol.2010.197491

Weir, E. K., Lopez-Barneo, J., Buckler, K. J., and Archer, S. L. (2005). Acute oxygen-sensing mechanisms. N. Engl. J. Med. 353, 2042-2055. doi: 10.1056/NEJMra050002

Zhang, M., Buttigieg, J., and Nurse, C. A. (2007). Neurotransmitter mechanisms mediating low-glucose signalling in cocultures and fresh tissue slices of rat carotid body. J. Physiol. 578, 735-750. doi: 10.1113/jphysiol.2006. 121871
Conflict of Interest Statement: The authors declare that the research was conducted in the absence of any commercial or financial relationships that could be construed as a potential conflict of interest.

Received: 31 July 2014; accepted: 25 September 2014; published online: 15 October 2014.

Citation: Gao L, Ortega-Sáenz P, García-Fernández M, González-Rodríguez P, Caballero-Eraso C and López-Barneo J (2014) Glucose sensing by carotid body glomus cells: potential implications in disease. Front. Physiol. 5:398. doi: 10.3389/fphys. 2014.00398

This article was submitted to Integrative Physiology, a section of the journal Frontiers in Physiology.

Copyright (C) 2014 Gao, Ortega-Sáenz, García-Fernández, González-Rodríguez, Caballero-Eraso and López-Barneo. This is an open-access article distributed under the terms of the Creative Commons Attribution License (CC BY). The use, distribution or reproduction in other forums is permitted, provided the original author $(s)$ or licensor are credited and that the original publication in this journal is cited, in accordance with accepted academic practice. No use, distribution or reproduction is permitted which does not comply with these terms. 